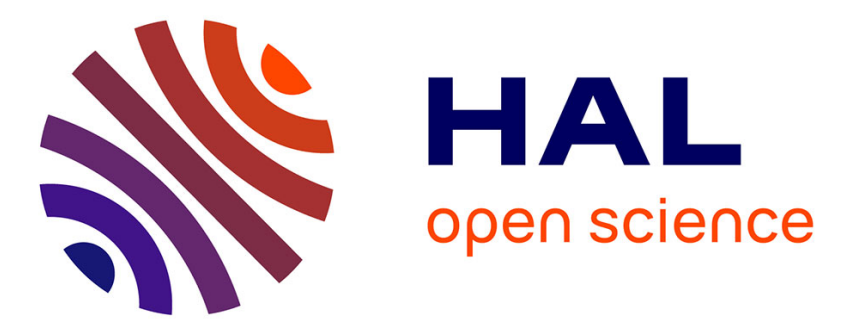

\title{
On the generation of bionic pulses with conventional piezoelectric transducers by proper design of the input driving function
}

P. Cobo-Parra, R. Carbó-Fité

\section{- To cite this version:}

P. Cobo-Parra, R. Carbó-Fité. On the generation of bionic pulses with conventional piezoelectric transducers by proper design of the input driving function. Journal de Physique IV Proceedings, 1994, 04 (C5), pp.C5-339-C5-342. 10.1051/jp4:1994570 . jpa-00253065

\section{HAL Id: jpa-00253065 \\ https://hal.science/jpa-00253065}

Submitted on 1 Jan 1994

HAL is a multi-disciplinary open access archive for the deposit and dissemination of scientific research documents, whether they are published or not. The documents may come from teaching and research institutions in France or abroad, or from public or private research centers.
L'archive ouverte pluridisciplinaire HAL, est destinée au dépôt et à la diffusion de documents scientifiques de niveau recherche, publiés ou non, émanant des établissements d'enseignement et de recherche français ou étrangers, des laboratoires publics ou privés. 


\title{
On the generation of bionic pulses with conventional piezoelectric transducers by proper design of the input driving function
}

\author{
P. COBO-PARRA and R. CARBÓ-FITÉ \\ Instituto de Acústica (C.S.I.C.), Serrano 144, 28006 Madrid, Spain
}

\begin{abstract}
This paper concerns with the capacity of piezoelectric transducers to generate bionic pulses, by proper design of the input driving function which equalizes their transfer function. Firstly, the transfer function is measured by performing the transducer in the pinger mode. The measured transfer function, together with the parameters of the desired bionic pulse (i.e. central frequency, stretching and chirp), are the inputs to a program to calculate the voltage function which should drive the transducer. Finally, the transducer is driven with the calculated voltage function, synthesized by an arbitrary waveform generator, and the transmitted acoustic pulse is measured. Theoretical bionic pulses and experimental pulses synthesized by this method show an excellent agreement.
\end{abstract}

\section{INTRODUCTION}

We are acquainted with the use of pulsed transducers for active sonar systems. These kinds of systems radiate to the water a repetitive train of pulsed tones and measure the range and bearing between the source and the target. Since the transducer is characterized by a given impulse response, fixing the input driving function also fix the pulse waveform transmitted to the water. Hence, this driving way to perform a transducer is non versatile.

The animal echolocation systems, however, are versatile. This means that they adapt the transmitted acoustic pulse to the particular location problem at hand. When the target is far away they emit a lowrate train of long FM pulses. When they approach the target, they increase the rate and decrease the length of the pulse train.

Signal processing provides a tool to design more versatile sonar pulses. Holly [1] reported a Wiener filtering method to generate broadband acoustic transmissions. Cobo and Carbó [2] showed that inverse filtering can be used to design the input voltage which equalizes the transfer function of the transducer. They reported a drastic reduction of the $Q$ factor of a conventional $106 \mathrm{kHz}$ piezoelectric transducer from $\mathrm{Q}=14.7$, in pinger mode, to $\mathrm{Q}=1.65$, in equalized mode, with the cost of an amplitude loss amounting $33 \%$. Piquette [3-4] used the equivalent circuit of the transducer to design the input driving voltage that cancels out the turnon and turnoff transients of the transmitted pulse. 
This paper concerns with the generation of bionic pulses with conventional transducers. According to Altes [5] bionic pulses have the following properties :

1. They simulate closely the sonar pulses emitted by delphinids.

2. They provide a constant TW which simplifies the design of matched filters to analyze generalized targets.

3. They are free of range-doppler coupling.

4. They are optimally tolerants to doppler.

\section{METHODS}

\subsection{Design of the driving function}

In conventional performance, a transducer driven with a burst-type voltage, $x_{c}(t)$, transmits to the load an acoustic pulse, $y_{c}(t)$, given by

$$
y_{c}(t)=h(t)^{*} x_{c}(t)
$$

where $h(t)$ is the impulse response of the transducer and * denotes convolution. In the frequency domain, the transfer function, $\mathrm{H}(\mathrm{f})$, is

$$
H(f)=\frac{Y_{c}(f)}{X_{c}(f)}
$$

where $X_{c}(f)$ and $Y_{c}(f)$, the Fourier transforms of $x_{c}(t)$ and $y_{c}(t)$, respectively, are the input and output spectra. Now, instead of fixing the input voltage, let us prescribe the output waveform, $y_{p}(t)$. The necessary input spectrum to obtain such an acoustic spectrum, $X_{p}(f)$, should be

$$
X_{p}(f)=\frac{Y_{p}(f)}{H(f)}
$$

and, including eq. (1b) for the transfer function

$$
X_{p}(f)=Y_{p}(f) \frac{X_{c}(f)}{Y_{c}(f)}
$$

Therefore, to determine the necessary input voltage, we only need:

1. The direct Fourier transform of the easily measured input voltage and output acoustic pulse, in conventional performance.

2. To choose the spectrum of the desired pulse.

3. The inverse Fourier transform of the necessary voltage spectrum, calculated according to eq. (2b). 
Then, this voltage function should be implemented either by suitably driving a digital filter, as made by Holly [1], or by sending this function to the bank memory of an arbitrary waveform generator, as made by Cobo and Carbó [2].

If $Y_{p}(f)=1$, the spectrum for a spike, $X_{p}(f)=1 / H(f)$, the inverse of the transfer function. Thus, ideal equalization is equivalent to inverse filtering (or spiking deconvolution). In this case, we shape a bionic spectrum, as given in the next Section.

\subsection{Bionic pulses}

According to Altes [5], the spectrum of the bionic pulse can be given by

$Y_{p}=\left\{\begin{array}{rrr}\text { cte } e^{-\left[\ln \left(f / f_{0}\right)\right]^{2} / 2 \ln k} & e^{-j 2 \pi a \ln \left(f / f_{0}\right) / \ln k} & f \geq 0 \\ 0 & f<0\end{array}\right.$

where $\mathrm{f}_{0}$ is the central frequency of the magnitude spectrum, $k$ is the stretching parameter governing the bandwidth of the pulse, and $a$ is the chirp parameter giving the sweeping of the phase spectrum. The waveform of the corresponding pulse is calculated from $y_{p}(t)=\operatorname{Real}\left\{f-1\left[Y_{p}(f)\right]\right\}$. The effective duration of the pulse depends on the combination of $k$ and $a$ parameters. Greater values of $k$ afford wider frequency bands and therefore shorter pulses. However, greater values of $a$ provide larger pulses with more zero crossings and higher frequency modulation.

\section{RESULTS}

Figure 1 shows the results of applying this technique to the generation of bionic pulses with a $106 \mathrm{kHz}$ sandwich transducer. Figures $1 \mathrm{a}$ and $\mathrm{lb}$ are the driving voltage input and the transmitted acoustic pulse, respectively, in pinger mode. The $\mathrm{f}_{0}$ and $k$ parameters of the corresponding bionic pulse were chosen according with the amplitude spectrum of the ping in Figure $1 \mathrm{~b}$. The bionic pulse for the parameter series $\left\{\mathrm{f}_{0}, k, a\right\}=\{106 \mathrm{kHz}, 1.02,-0.5\}$ is shown in Figure 1d. The sandwich transducer should be driven with the voltage function shown in Figure 1c. This driving function was synthesized with a programmable arbitrary waveform generator.

\section{CONCLUSIONS}

We have presented a method to enforce a conventional sandwich transducer to generate bionic pulses. Instead of driving the transducer with a conventional gated-sine function, we prescribe the desired acoustic waveform and we synthesize the necessary voltage function, provided that we previously measure the transfer function of the transducer. Bionic waveforms depend on three parameters: $f_{0}$, the central frequency of the spectrum, $k$, which determines the spectral bandwidth, and $a$, that determines the slope of the spectral phase function and is related to the chirp in the time waveform.

\section{Acknowledgments}

This research was carried out with financial support of the "Comunidad Autonoma de Madrid" under the Project 171/92. 

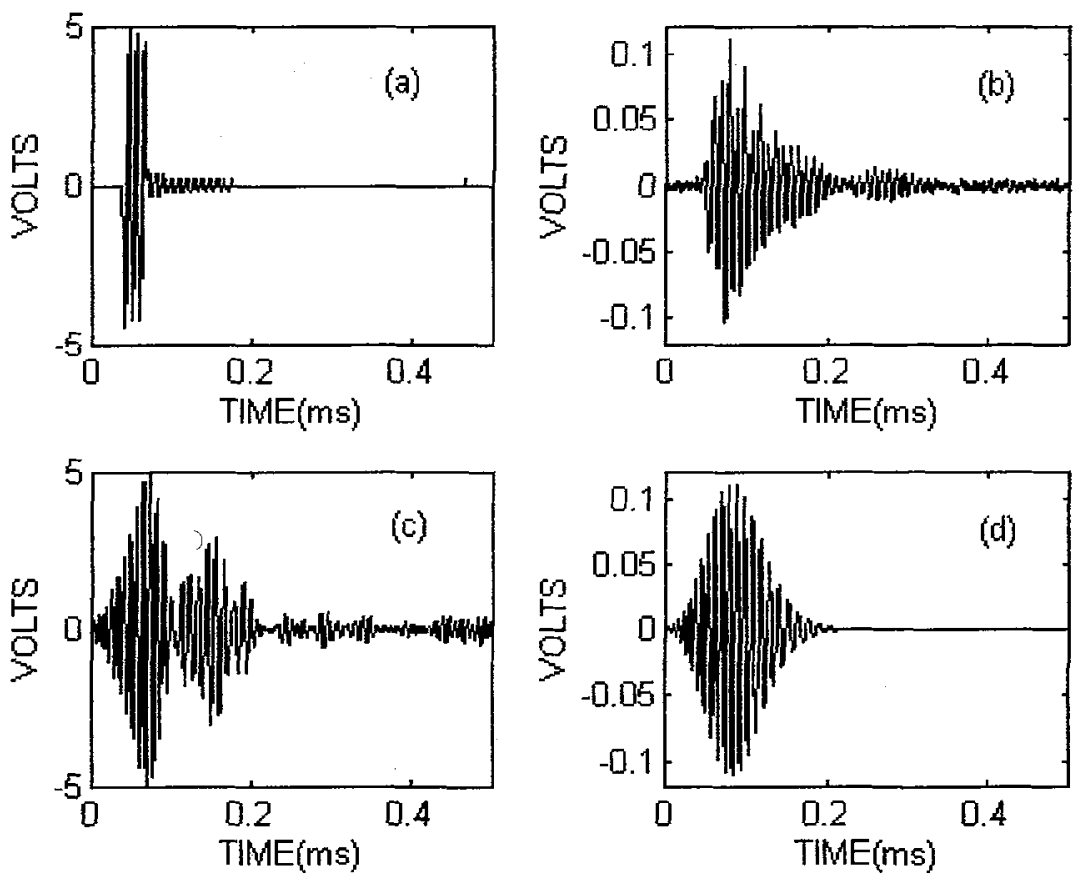

Figure 1. Input driving voltage (left) and transmitted acoustic pulse (right) in pinger mode (above) and bionic mode (below) for the parameter series $\left\{f_{0}, k, a\right\}=\{106 \mathrm{kHz}, 1.02,-0.5\}$

\section{REFERENCES}

[1] Holly, A.C., "A method for the generation of broadband acoustic transmissions". J. Acoust. Soc. Am. 75 (1984) 973-976.

[2] Cobo, P. and Carbó, R., "Parametric equalization of sonar transducers by shaping pre-filtering and its effect on the directivity pattern". Acta Acústica 1 (1993) 101-109.

[3] Piquette, J.C., "Method for transducer transient suppression. I: Theory". J. Acoust. Soc. Am. 92 (1992) 1203-1213.

[4] Piquette, J.C., "Method for transducer transient suppression. I: Experiment". J. Acoust. Soc. Am. 92 (1992) 1214-1221.

[5] Altes, R.A., "Sonar for generalized target description and its similarity to animal echolocation systems". J. Acoust. Soc. Am. 59 (1976) 97-105. 